\title{
Therapeutic Strategy for Gastrointestinal Bleeding in Patients With Left Ventricular Assist Device
}

\author{
Teruhiko Imamura, MD, PhD; Koichiro Kinugawa, MD, PhD; Nir Uriel, MD
}

\begin{abstract}
Left ventricular assist device (LVAD) technology has improved the survival of advanced heart failure patients. However, readmission rates following LVAD implantation remain high and are an unsolved matter. Currently, gastrointestinal bleeding is one of the major causes of readmission and has recently been demonstrated to mainly result from increased angiogenesis. In addition to the conventional therapeutic strategies, including a reduction in antiplatelet and anticoagulation therapies and blood products administration, several therapeutic tools have recently been proposed: octreotide, thalidomide, hemodynamic optimization by the ramp test, and fish oil therapy. This review will update the therapeutic strategy for gastrointestinal bleeding in LVAD patients.
\end{abstract}

Key Words: Angiogenesis; HeartMate; Hemocompatibility; Left ventricular assist device (LVAD); Omega-3

I mprovements in the technology of continuous-flow left ventricular assist devices (LVADs; Figure 1) has changed the clinical course of advanced heart failure (HF) patients, with significant improvement in survival rate. In the most recent study, the HeartMate 3, a novel completely magnetic levitated centrifugal LVAD, was demonstrated to have as high survival rate as that of heart transplantation at 2-year follow-up $(83 \%) . \mathbf{1 , 2}$ However, a high readmission rate following implantation is still reported with all LVADs. ${ }^{3}$ In general, hemocompatibilityrelated adverse events (HRAEs), ${ }^{4}$ comprsing both bleeding and thrombotic events (gastrointestinal bleeding [GIB], neurologic events, pump thrombosis and other thromboembolic events) are the leading causes of readmission, and specifically, GIB is the most common comorbidity. ${ }^{5}$

The incidence of GIB varies with institute and device type $(\approx 10-40 \%){ }^{6-10}$ For example, $27 \%$ of the patients supported with HeartMate 3 in the MOMENTUM 3 study 1 and $35.1 \%$ of patients supported with HVAD (HeartWare, Medtronic) in the ENDURANCE study experienced GIB at 2 years. ${ }^{11}$ Although there was no significant reduction in the rate of GIB in those 2 studies as compared with HeartMate II $(27.3 \%$ and $34.2 \%$, respectively $){ }^{1}$ similar rates of GIB were reported in Europe during the HM $3 \mathrm{CE}$ mark study $(12 \%$ at 1 year $) .{ }^{12}$

The situation is a little different in Japan, and the Japanese registry for Mechanically Assisted Circulatory Support has reported 0.29 events/year of all-cause bleeding rate (including GIB). ${ }^{13}$ Considering that this rate includes all-cause bleeding, the GIB rate would be significantly lower than in Europe and the USA. We hypothesize that the difference in the GIB rate between countries may be the key to approaching novel therapies of $\mathrm{GIB},{ }^{14}$ which will be discussed later. Despite the low rate of GIB in Japan, a cer- tain number of Japanese patients still suffer from refractory GIB. Considering the current, increasing number of LVAD implantations, together with the upcoming approval of destination therapy indication, Japanese clinicians should also understand the management of GIB. In this review, we will approach the mechanism of GIB considering recent accumulating evidence, and introduce conventional and several updated therapeutic strategies for GIB.

\section{Pathophysiology of GIB in LVAD Patients}

\section{Antiplatelet and Anticoagulation Therapies}

Multiple conditions in the field of cardiology require the chronic use of antiplatelet and anticoagulation drugs alone or in combination, but none report such a high rate of GIB as we experience in LVAD patients. For example, significant all-cause bleeding occurred at $3.57 \%$ per year during anticoagulation therapy in patients with atrial fibrillation in the RE-LY trial. ${ }^{15}$ Significant all-cause bleeding occurred at $0.9 \%$ per year in patients receiving anticoagulation therapy to treat deep venous thrombosis in the PREVENT trial. ${ }^{16}$ The rate of GIB during a 6-month antiplatelet therapy with aspirin and clopidogrel following percutaneous coronary intervention was $1.1 \%$ with a proton pump inhibitor and $2.9 \%$ with a placebo in the COGENT trial. ${ }^{17}$

GIB during LVAD support is not similar to these other conventional situations ${ }^{\mathbf{1 8}}$ and is sometimes refractory to discontinuation of antiplatelet and anticoagulation therapies. ${ }^{19}$ The mechanism of GIB during LVAD support may not be simply explained by concomitant antiplatelet and anticoagulation therapies.

Received August 6, 2018; revised manuscript received October 10, 2018; accepted October 16, 2018; released online October 27,2018

Department of Medicine, University of Chicago Medical Center, Chicago, IL (T.I., N.U.), USA; Second Department of Internal Medicine, Toyama University, Toyama (K.K.), Japan

Mailing address: Koichiro Kinugawa, MD, PhD, Second Department of Internal Medicine, Toyama University, 2630 Sugitani, Toyama 930-0194, Japan. E-mail: kinugawa-tky@umin.ac.jp

ISSN-1346-9843 All rights are reserved to the Japanese Circulation Society. For permissions, please e-mail: cj@j-circ.or.jp 


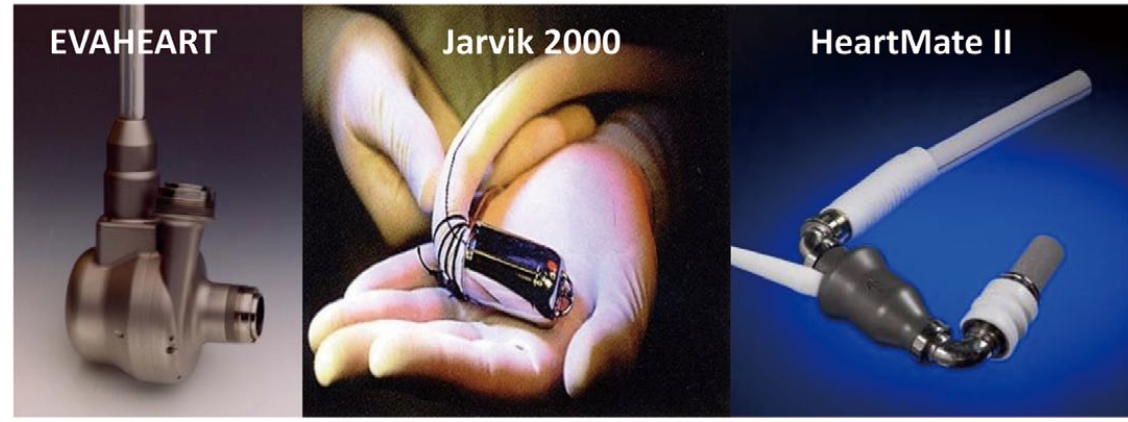

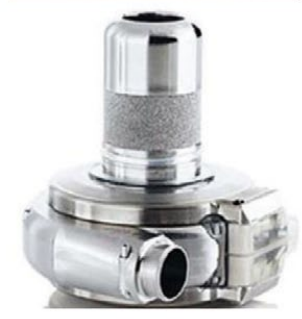

HVAD

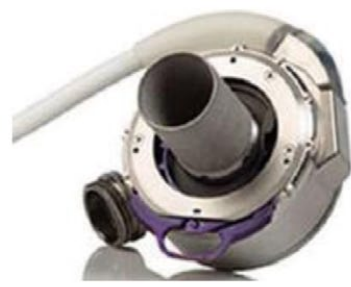

HeartMate 3

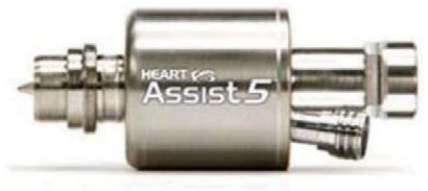

HeartAssist5
Figure 1. Left ventricular assist devices available in Japan and the USA.

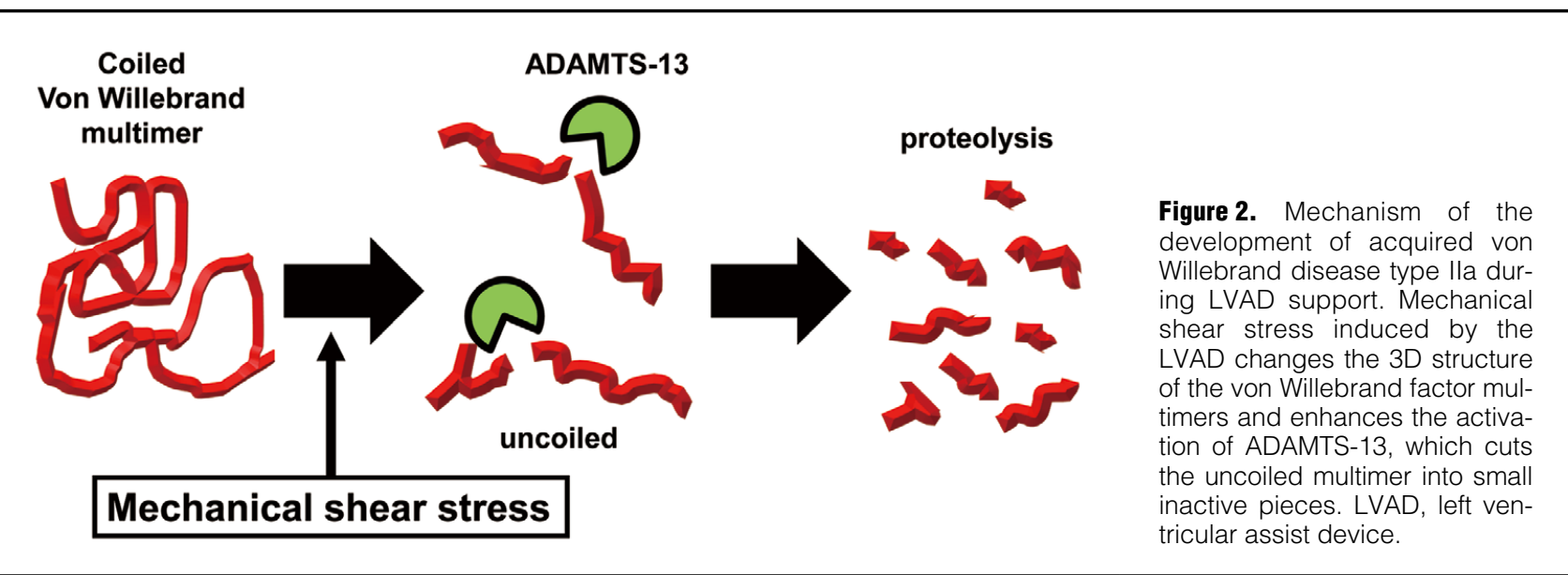

\section{Acquired von Willebrand Disease Type lla}

von Willebrand factor (vWF) is critical to hemostasis by acting as a bridging molecule at sites of vascular injury for normal platelet adhesion, as well as promoting platelet aggregation under conditions of high shear. ${ }^{20}$ The development of acquired von Willebrand disease in cardiology was first reported in patients with aortic valve stenosis and is related to the high shear stress caused by narrowing of the aortic valve. ${ }^{21}$

All continuous-flow LVAD, including axial-flow (HeartMate II, Jarvik 2000, and HeartAssist 5) and centrifugal (HVAD and HeartMate 3 ) devices, are associated with high shear stress and as such with the development of acquired von Willebrand disease type IIa. The high shear stress between blood and pump alters the 3D structure of the large VWF multimers and enhances its proteolysis by ADAMTS-13 (Figure 2).22,23 The loss of large vWF multimers is associated with reduced aggregation of platelets and increased GIB rate in LVAD patients. ${ }^{9}$

Acquired von Willebrand disease type IIa has been reported with various types of LVADs, ${ }^{24,25}$ and the incidence and magnitude of this disease varies with each type of LVAD. The EVAHEART LVAD causes significantly less vWF degradation than the HeartMate II. ${ }^{26}$ In recent study by Netuka et al, a lower rate of acquired von Willebrand disease type IIa was reported in patients supported with HeartMate 3 compared with patients supported with HeartMate II. ${ }^{27}$ However, as stated before, a similar rate of GIB between the pumps has been reported. Currently, it is known that there is not a linear correlation between the activities of von Willebrand disease type IIa and the magnitude or refractoriness of GIB. Considering that not all LVAD patients with acquired von Willebrand disease type IIa experience GIB, this phenomenon may not be the sole explanation of the high rate of GIB in LVAD patients. 


\section{Arteriovenous Malformation (AVM)}

Anatomically, it has been reported that the major cause of GIB during LVAD support is an AVM in the digestive duct lumen (Figure 3), ${ }^{10,28}$ and recent studies, including ours, have focused on the angiogenesis-related signal cascade associated with LVAD support as a major cause of AVM (Figure 4). ${ }^{29,30}$

The elevated level of tumor necrosis factor (TNF)- $\alpha$ facilitates pericyte apoptosis and reduces the expression of angiopoietin-1, and destabilizes endothelial cells. Also, the increase in TNF- $\alpha$ enhances the expression of tissue factor and the generation of thrombin. Expression of angiopoietin-2 is then increased and proliferation of endothelial cells is induced..$^{30}$ These 2 cascades result in the formation of AVMs in LVAD patients. We consistently demonstrated that LVAD patients with elevated TNF- $\alpha$ and angiopoietin- 2 experienced more GIB compared with others. ${ }^{29}$

This activation of inflammation and angiogenesis is already observed in patients with advanced HF before LVAD implantation. Consistently, the prevalence of nasal hypervascularity, which is associated with the development of GIB, in patients with advanced HF, is as high as in those with LVAD support. ${ }^{31}$ However, the severity of nasal hypervascularity is lower in the HF group compared with the LVAD group. Furthermore, we reported recently, in a subanalysis of the PREVENT biobank study, that elevated TNF- $\alpha$ and angiopoietin-2 levels prior to LVAD implantation were associated with high bleeding rates following LVAD implantation. ${ }^{32}$ The interaction between the device and blood following LVAD implantation may stimulate the excretion of TNF- $\alpha$ and lead to a more abnormal angiogenesis cascade. ${ }^{29}$

\section{Management and Prevention of GIB}

\section{Diagnosis of GIB}

Diagnosing GIB during LVAD support is similar to that for conventional GIB in other situations. GIB is defined according to the Interagency Registry for Mechanically Assisted Circulatory Support as any clinically suspected or documented bleeding from the GI tract as indicated by a new drop in hemoglobin and the appearance of melena, hematochezia, hematemesis, or guaiac-positive stool.

\section{Management of GIB}

Current methodologies to manage and prevent GIB are

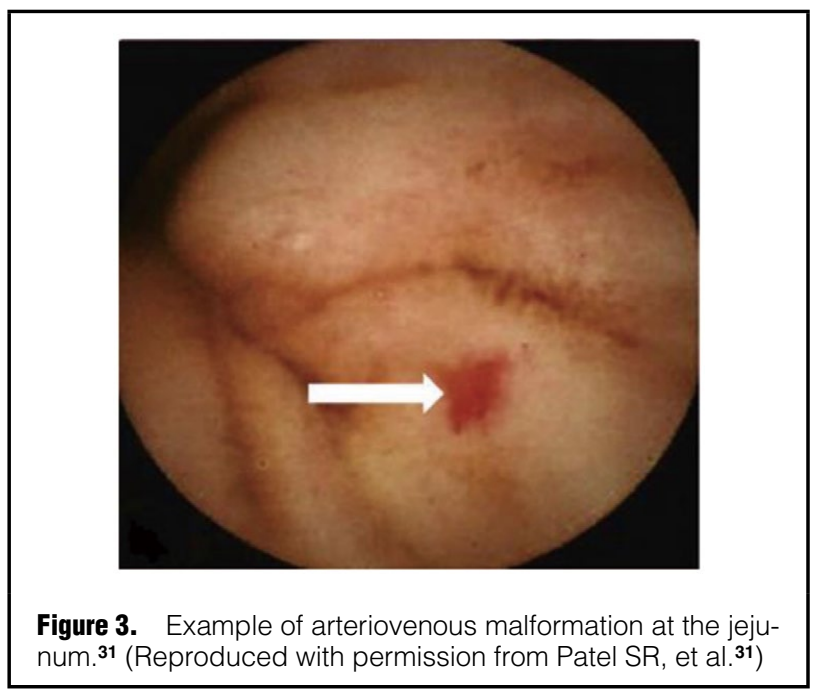

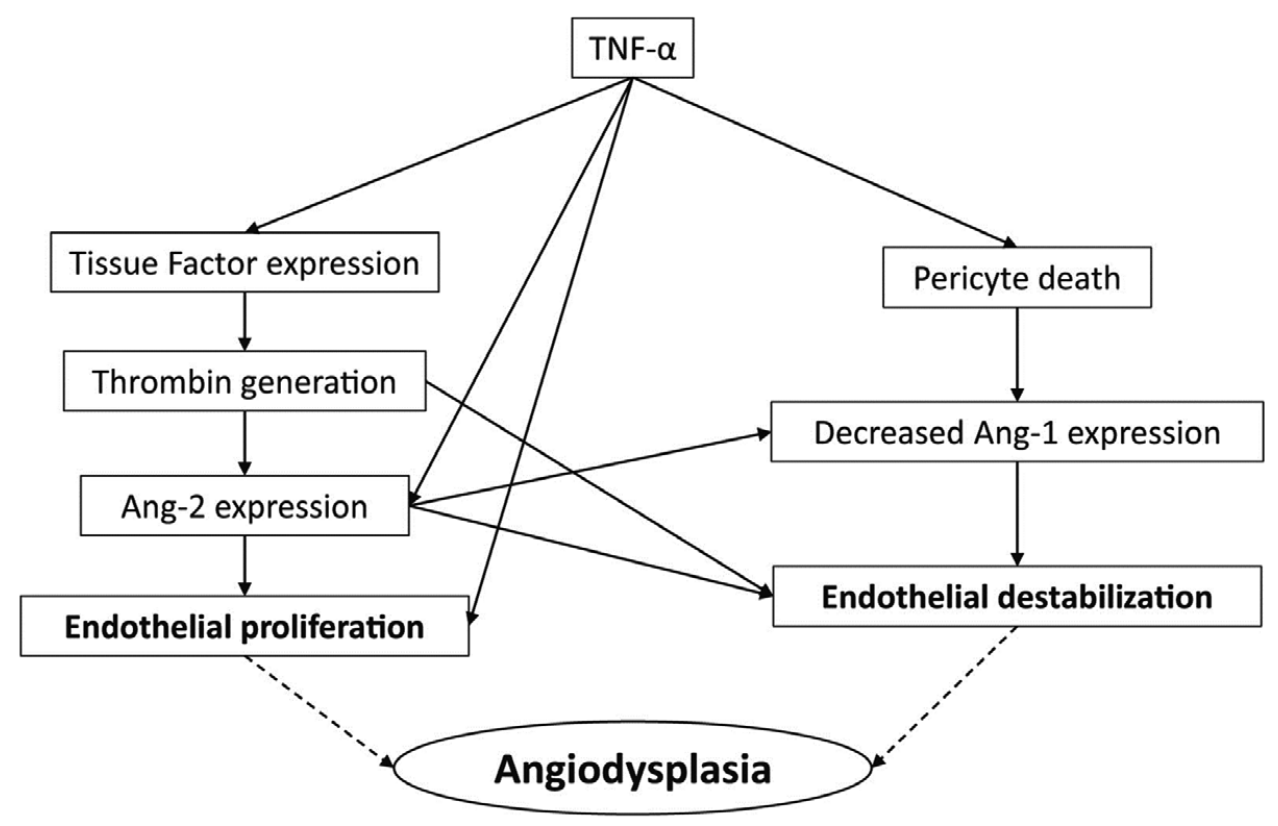

Figure 4. Angiogenesis-related cascade to angiodysplasia. ${ }^{29}$ (Reproduced with permission from Tabit CE, et al. ${ }^{29}$ ) 


\begin{tabular}{|c|c|}
\hline Purpose & Methodology \\
\hline \multirow{5}{*}{ Management of GIB } & Discontinuation of antiplatelet and anticoagulation therapies \\
\hline & Proton pump inhibitor \\
\hline & Invasive endoscopic cauterization \\
\hline & Endovascular embolization \\
\hline & Blood products administration \\
\hline \multicolumn{2}{|l|}{ Prevention of GIB } \\
\hline \multirow[t]{3}{*}{ Secondary prevention } & Reduction in antiplatelet and anticoagulation therapies \\
\hline & Octreotide therapy \\
\hline & Danazol and thalidomide therapies \\
\hline \multirow[t]{4}{*}{ Primary prevention } & (Reduction in antiplatelet and anticoagulation therapies) \\
\hline & LVAD speed adjustment and hemodynamic optimization \\
\hline & Anti-heart failure medications \\
\hline & Omega-3 therapy \\
\hline
\end{tabular}

GIB, gastrointestinal bleeding; LVAD, left ventricular assist device.

\begin{tabular}{|c|c|c|}
\hline Intensity & Clinical components & Score \\
\hline Tier I: mild & $\begin{array}{l}\leq 2 \text { gastrointestinal or other nonbleeding episodes } \\
\text { Suspected pump thrombosis (medically treated) } \\
\text { Nonstroke-related neurological events } \\
\text { Arterial thromboembolism not resulting in organ loss }\end{array}$ & 1 point each \\
\hline Tier II: moderate & $\begin{array}{l}\text { >2 gastrointestinal or other nonbleeding episodes } \\
\text { Nondisabling stroke } \\
\text { Arterial thromboembolism resulting in organ loss }\end{array}$ & 2 points each \\
\hline $\begin{array}{l}\text { Tier III } \\
\text { IIIA: moderate to severe }\end{array}$ & $\begin{array}{l}\text { Pump malfunction attributable to pump thrombosis leading to } \\
\text { reoperation for removal or replacement }\end{array}$ & 3 points each \\
\hline IIIB: severe & $\begin{array}{l}\text { Disabling stroke } \\
\text { Death attributable to hemocompatibility or inconclusive }\end{array}$ & 4 points each \\
\hline
\end{tabular}

The table has been reproduced with permission from Uriel N, et al. ${ }^{38}$

listed in Table 1. Therapies to address ongoing GIB include temporary discontinuation of anticoagulant and antiplatelet medications, ${ }^{33}$ intravenous administration of proton pump inhibitors, ${ }^{\mathbf{1 8}}$ and invasive endoscopic cauterization to investigate the cause(s) of bleedings and directly treat them..$^{34}$ In rare cases, administration of vitamin $K$, fresh frozen plasma, cryoprecipitate or concentrated vWF are given for refractory bleeding episodes, but these agents may increase the risk of pump thrombosis. ${ }^{35}$ In cases where an endoscopic approach has failed, endovascular embolization is used to terminate the bleeding. ${ }^{36}$ Device type may also need to be considered when these approaches are adopted, because of differences in hemocompatibility between devices. Most of the evidence is derived from Western countries, where patients' body surface area is higher. The results may not be simply applied in Japanese populations, where patients have a smaller body surface

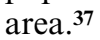

To date, a definitive strategy to manage GIB has not been identified, probably because none of these procedures directly approaches the major cause of GIB (i.e., AVM). Furthermore, any therapy that modifies hemocompatibility can effect another HRAE. ${ }^{4}$ For example, discontinuation of anticoagulation drugs may reduce the risk of bleeding, but increase the risk of thrombotic complications. To determine the aggregate net burden of HRAEs, instead of assessing each type of event, it may be useful to adopt a hemocompatibility score (HCS), which is a tiered hierarchal score and weights each HRAE based on its escalating clinical relevance. The definitions of each tier and weighted score are shown in Table $2 .{ }^{38}$ HCS may be useful to evaluate the efficacy of any therapy on total hemocompatibility including both bleeding and thrombotic events.

\section{Secondary Prevention of GIB}

GIB during LVAD support occurs repeatedly, and the secondary prevention of GIB is of great concern. After active GIB resolves, anticoagulation is reintroduced using a device-specific international normalized ratio target. Antiplatelet therapy is typically held back or reintroduced at a reduced dose. With repeat bleeding episodes, the international normalized ratio target could be reduced or the anticoagulation therapy can be discontinued. ${ }^{35,39}$

For repeated GIB that is refractory to the conventional therapies described, octreotide, a somatostatin analog, may be considered. The mechanism by which octreotide 


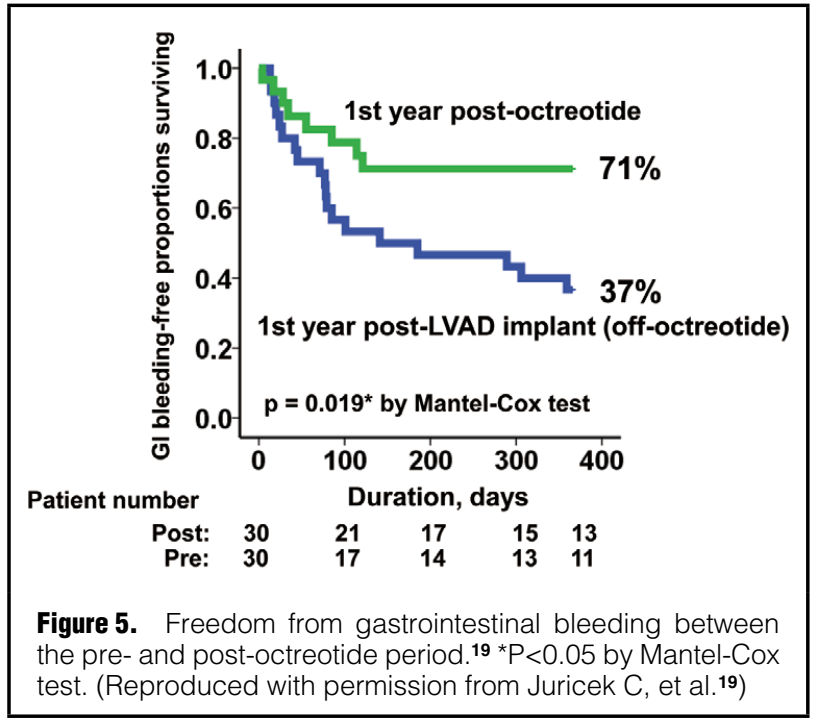

reduces GIB has not been well investigated. Contributing mechanisms are hypothesized to include decreases in portal vein pressure because of splanchnic vasodilatation, enhancement of platelet aggregation and inhibition of GI angiogenesis, as well as suppression of digestive enzymes. ${ }^{40}$

In addition to several previous studies of octreotide usage with small sample sizes, ${ }^{41-43}$ our team recently reported its advantage in secondary prevention of refractory GIB in LVAD patients. ${ }^{19}$ In our institutional protocol, LVAD patients with refractory GIB receive an intramuscular injection of $20 \mathrm{mg}$ of octreotide every 4 weeks. We demonstrated a significant reduction in the frequency of GIB during octreotide therapy without any associated complications, despite unchanged antiplatelet therapy and an increase in the level of anticoagulation therapy, as compared with the pre-octreotide period (Figure 5). A similar favorable result was recently demonstrated by a multicenter prospective study. ${ }^{44}$ The next step would be a randomized control trial for both primary and secondary prevention, with a focus on both efficacy and cost-effectiveness.

Other therapies such as danazol and thalidomide may have a potential hemostatic role in LVAD patients with refractory GIB. Danazol is a derivative of testosterone, which reduces the risk of bleeding via enhanced concentration of red blood cells. The mechanism of thalidomide therapy in suppressing recurrent GIB may be attributed to its antiangiogenic properties via suppression of vascular endothelial growth factor. ${ }^{45}$

These therapies lack sufficient evidence for routine clinical use, but can be administered orally and may be cheaper than octreotide. However, the adverse event profile for both agents is significant. Strict patient selection and careful monitoring are required for thalidomide therapy because of pancytopenia and neuropathy ${ }^{46,47}$ Patients may not tolerate long-term danazol therapy because of its androgenic effects. ${ }^{48}$ The relative efficacy, safety, and costeffectiveness of octreotide and these other agents should be investigated.

\section{Primary Prevention of GIB}

Thus far, there are no definitive therapies for the pri-

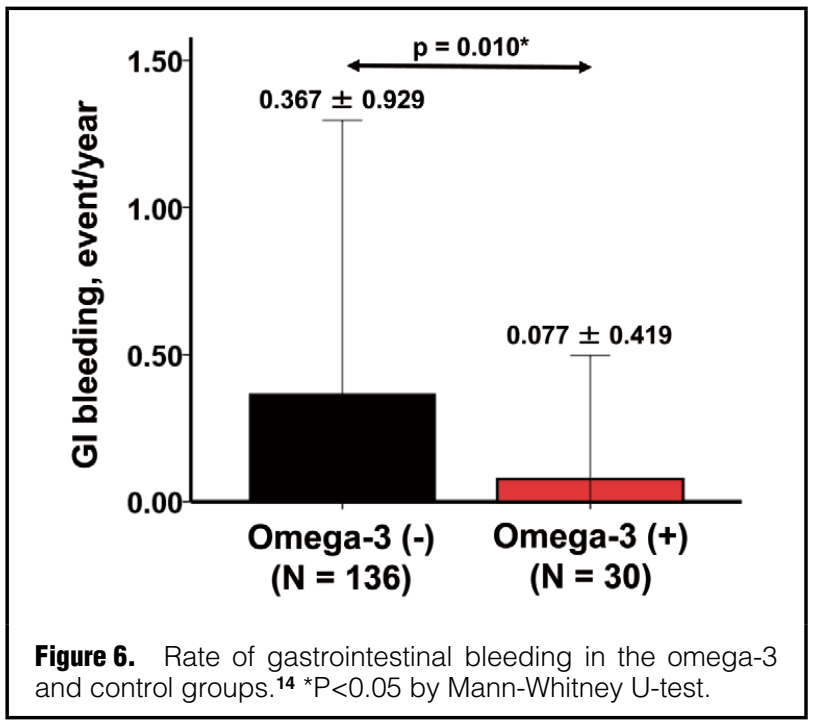

mary prevention of GIB during LVAD support. The MAGENTUM 1 study recently demonstrated in a small HeartMate 3 LVAD cohort that low-intensity anticoagulation targeting an international normalized ratio between 1.5 and 1.9 was achievable and safe during the 6 months post-implant, ${ }^{49}$ but further studies are warranted to investigate optimal antiplatelet and anticoagulation therapies for primary preventions of GIB with each type of LVAD and/or in each risk-stratified patient population. With regard to optimal medical therapy, direct oral anticoagulants may also be considered in the near future. ${ }^{\mathbf{5 0}}$

Some investigators have suggested that reducing the speed of the LVAD to promote aortic valve opening and enhance arterial pulsatility may be effective in reducing GIB. ${ }^{33}$ However, a recent study of a partial ventricular support device, in which arterial pulse pressure was fully preserved, reported a relatively high rate of GIB. ${ }^{51}$ This observation raises questions about the association of diminished pulsatility with the generation of AVM and increased bleeding risk. Inadequately reduced LVAD speed may instead cause hemodynamic deterioration.

Instead of just decreasing the LVAD's speed, hemodynamic optimization by LVAD speed adjustment through a ramp test may have an advantage in suppressing GIB.,52 Our team recently demonstrated that optimized hemodynamics were associated with reduced HRAEs, including a lower rate of GIB. ${ }^{53}$ HRAEs can be affected by hemodynamics. For example, right ventricular failure is one of the major risk factors of GIB in LVAD patients, because of enhanced AVM formation from the increase in portal vein pressure and coagulopathy associated with congestive hepatic failure. ${ }^{54,55}$

Anti-HF medications, including $\beta$-blockers and angiotensin-converting enzyme inhibitors, have strong evidence for suppressing the progression of $\mathrm{HF}, \mathbf{5 6 , 5 7}$ but less evidence in LVAD patients (level of evidence: $\mathrm{C}$ on ISHLT guideline). ${ }^{33} \mathrm{We}$ recently demonstrated that anti-HF medications were associated with reduced GIB rate in a retrospective LVAD patient cohort study. ${ }^{58}$ The precise mechanism remains uncertain, but improved hemodynamics may have a favorable effect in suppressing GIB as discussed earlier. ${ }^{53}$ Optimal doses of anti-HF medications 
remain uncertain.

Although these therapies may be promising tools for preventing GIB, they may not directly affect the formation of AVM via an angiogenesis-related pathway. Omega-3, an unsaturated fatty acid, is known to have inhibitory effects on angiogenesis and inflammation. ${ }^{59}$ Our team recently demonstrated that LVAD patients receiving omega-3 therapy had greater freedom from GIB at 1 year than the control group (Figure 6). ${ }^{\mathbf{1 4}}$ The implication of omega-3 therapy remained even after background matched analyses. The GIB rate in the omega-3 group was 0.08 events/year in our previous study, ${ }^{14}$ which was $79 \%$ lower than the rate of 0.37 events/year in the control group, and $84 \%$ lower than the rate of 0.49 events/year recently reported by INTERMACS (at 3-12 months following LVAD implantation). ${ }^{60}$ The rate of GIB in the omega-3 group was similar to the rate of all-cause bleeding reported by the Japanese registry for Mechanically Assisted Circulatory Support (0.12 events/year). ${ }^{13}$

One potential mechanism for the lower rates of GIB in Japan may be related to the Japanese diet, which is rich in fish oil containing omega-3. Further studies that compare angiogenesis-related biomarkers and GIB rates between the USA and Japan are warranted.

Omega-3 suppresses inflammation, angiogenesis, and cell proliferation and invasion via its effects on cyclooxygenase, lipoxygenase, and cytochrome P450 enzymes.61 The precise mechanism for omega-3 suppression of GIB remains uncertain, but the omega-3 may reduce the TNF-a level together with suppression of angiopoietin-2 expression, although there is no direct evidence for this relationship.

\section{Different Therapeutic Strategies in Japan and Western Countries}

As discussed before, the fish-rich diet in Japan may be one of the major reasons why Japanese LVAD patients rarely suffer GIB. Age is a well-known risk factor of GIB and other comorbidities,, $\mathbf{9 6 2}$ and the relatively younger age of Japanese LVAD candidates (because there is no indication of destination therapy) may explain why GIB is rare in Japan. Nevertheless, our ongoing study demonstrates that the GIB rate is still lower in Japan than in the USA in an age-matched comparison. The magnitude of acquired von Willebrand disease may differ between the countries. A relatively lower LVAD speed in Japan may also contribute to less development of AVM and thus a reduced GIB rate, although recent studies do not support this hypothesis. ${ }^{\mathbf{5 1}}$ Our team is now conducting various studies investigating the difference between Japan and Western countries in management strategies, genetic backgrounds, and the inflammatory and angiogenesis systems to clarify the mechanism of GIB and create a novel therapeutic strategy for GIB, which may be the tailor-made therapy considering each patient's risk of GIB.

\section{Conclusions}

GIB is a significant comorbidity during LVAD support. In addition to conventional therapies, several novel therapeutic strategies, such as omega-3 therapy, that directly target the formation of AVM may be promising to overcome this comorbidity. Further studies are warranted to demonstrate utility in real-world practice.

\section{Sources of Funding}

None.

\section{Disclosures}

T.I. receives a Postdoctoral Fellowship for Research Abroad from the Japan Society for the Promotion of Science. N.U. receives consultant fees and grant support from Abbott and Medtronic.

\section{References}

1. Mehra MR, Goldstein DJ, Uriel N, Cleveland JC Jr, Yuzefpolskaya M, Salerno C, et al. Two-year outcomes with a magnetically levitated cardiac pump in heart failure. $N$ Engl J Med 2018; 378: $1386-1395$.

2. Mehra MR, Naka Y, Uriel N, Goldstein DJ, Cleveland JC Jr, Colombo PC, et al. A fully magnetically levitated circulatory pump for advanced heart failure. $N$ Engl J Med 2017; 376: $440-450$.

3. Imamura T, Chung B, Nguyen A, Sayer G, Uriel N. Clinical implications of hemodynamic assessment during left ventricular assist device therapy. J Cardiol 2018; 71: 352-358.

4. Mehra MR. The burden of haemocompatibility with left ventricular assist systems: A complex weave. Eur Heart J, doi:10.1093/eurheartj/ehx036.

5. Hasin T, Marmor Y, Kremers W, Topilsky Y, Severson CJ, Schirger JA, et al. Readmissions after implantation of axial flow left ventricular assist device. J Am Coll Cardiol 2013; 61: 153163.

6. Wever-Pinzon O, Selzman CH, Drakos SG, Saidi A, Stoddard GJ, Gilbert EM, et al. Pulsatility and the risk of nonsurgical bleeding in patients supported with the continuous-flow left ventricular assist device HeartMate II. Circ Heart Fail 2013; 6: $517-526$.

7. Aggarwal A, Pant R, Kumar S, Sharma P, Gallagher C, Tatooles $\mathrm{AJ}$, et al. Incidence and management of gastrointestinal bleeding with continuous flow assist devices. Ann Thorac Surg 2012; 93: $1534-1540$

8. Kushnir VM, Sharma S, Ewald GA, Seccombe J, Novak E, Wang IW, et al. Evaluation of GI bleeding after implantation of left ventricular assist device. Gastrointest Endosc 2012; 75: $973-$ 979.

9. Uriel N, Pak SW, Jorde UP, Jude B, Susen S, Vincentelli A, et al. Acquired von Willebrand syndrome after continuous-flow mechanical device support contributes to a high prevalence of bleeding during long-term support and at the time of transplantation. J Am Coll Cardiol 2010; 56: 1207-1213.

10. Demirozu ZT, Radovancevic R, Hochman LF, Gregoric ID, Letsou GV, Kar B, et al. Arteriovenous malformation and gastrointestinal bleeding in patients with the HeartMate II left ventricular assist device. J Heart Lung Transplant 2011; 30: 849-853.

11. Rogers JG, Pagani FD, Tatooles AJ, Bhat G, Slaughter MS, Birks EJ, et al. Intrapericardial left ventricular assist device for advanced heart failure. N Engl J Med 2017; 376: 451-460.

12. Krabatsch T, Netuka I, Schmitto JD, Zimpfer D, Garbade J, Rao V, et al. Heartmate 3 fully magnetically levitated left ventricular assist device for the treatment of advanced heart failure -1 year results from the Ce mark trial. J Cardiothorac Surg 2017; 12: 23 .

13. Nakatani T, Sase K, Oshiyama H, Akiyama M, Horie M, Nawata K, et al. Japanese registry for mechanically assisted circulatory support: First report. J Heart Lung Transplant 2017; 36: $1087-1096$.

14. Imamura T, Nguyen A, Rodgers D, Kim G, Raikhelkar J, Sarswat N, et al. Omega-3 therapy is associated with reduced gastrointestinal bleeding in patients with continuous-flow left ventricular assist device. Circ Heart Fail 2018; 11: e005082.

15. Connolly SJ, Ezekowitz MD, Yusuf S, Eikelboom J, Oldgren J, Parekh A, et al. Dabigatran versus warfarin in patients with atrial fibrillation. $N$ Engl J Med 2009; 361: 1139-1151.

16. Ridker PM, Goldhaber SZ, Danielson E, Rosenberg Y, Eby CS, Deitcher SR, et al. Long-term, low-intensity warfarin therapy for the prevention of recurrent venous thromboembolism. $N$ Engl $J$ Med 2003; 348: 1425-1434.

17. Bhatt DL, Cryer BL, Contant CF, Cohen M, Lanas A, Schnitzer TJ, et al. Clopidogrel with or without omeprazole in coronary artery disease. $N$ Engl J Med 2010; 363: 1909-1917.

18. Lau JY, Leung WK, Wu JC, Chan FK, Wong VW, Chiu PW, et al. Omeprazole before endoscopy in patients with gastrointesti- 
nal bleeding. $N$ Engl J Med 2007; 356: 1631-1640.

19. Juricek C, Imamura T, Nguyen A, Chung B, Rodgers D, Sarswat $\mathrm{N}$, et al. Long-acting octreotide reduces the recurrence of gastrointestinal bleeding in patients with a continuous-flow left ventricular assist device. J Card Fail 2018; 24: 249-254.

20. Proudfoot AG, Davidson SJ, Strueber M. von Willebrand factor disruption and continuous-flow circulatory devices. J Heart Lung Transplant 2017; 36: 1155-1163.

21. Heyde E. Gastrointestinal bleeding in aortic stenosis. $N$ Engl J Med 1958; 259: 196.

22. Siedlecki CA, Lestini BJ, Kottke-Marchant KK, Eppell SJ, Wilson DL, Marchant RE. Shear-dependent changes in the three-dimensional structure of human von Willebrand factor. Blood 1996; 88: 2939-2950.

23. Zhou Z, Nguyen TC, Guchhait P, Dong JF. Von Willebrand factor, ADAMTS-13, and thrombotic thrombocytopenic purpura. Semin Thromb Hemost 2010; 36: 71-81.

24. Sponga S, Nalli C, Casonato A, Charbonneau E. Severe upper gastrointestinal bleeding in Heartmate II induced by acquired von Willebrand deficiency: Anticoagulation management. Ann Thorac Surg 2012; 94: e41-e43.

25. Birschmann I, Dittrich M, Eller T, Wiegmann B, Reininger AJ, Budde $\mathrm{U}$, et al. Ambient hemolysis and activation of coagulation is different between HeartMate II and HeartWare left ventricular assist devices. J Heart Lung Transplant 2014; 33: 80-87.

26. Bartoli CR, Kang J, Zhang D, Howard J, Acker M, Atluri P, et al. Left ventricular assist device design reduces von Willebrand factor degradation: A comparative study between the HeartMate II and the EVAHEART left ventricular assist system. Ann Thorac Surg 2017; 103: 1239-1244.

27. Netuka I, Kvasnicka T, Kvasnicka J, Hrachovinova I, Ivak P, Marecek F, et al. Evaluation of von Willebrand factor with a fully magnetically levitated centrifugal continuous-flow left ventricular assist device in advanced heart failure. J Heart Lung Transplant 2016; 35: 860-867.

28. Letsou GV, Shah N, Gregoric ID, Myers TJ, Delgado R, Frazier $\mathrm{OH}$. Gastrointestinal bleeding from arteriovenous malformations in patients supported by the Jarvik 2000 axial-flow left ventricular assist device. J Heart Lung Transplant 2005; 24: $105-109$.

29. Tabit CE, Coplan MJ, Chen P, Jeevanandam V, Uriel N, Liao JK. Tumor necrosis factor-alpha levels and non-surgical bleeding in continuous-flow left ventricular assist devices. J Heart Lung Transplant 2018; 37: 107-115.

30. Tabit CE, Chen P, Kim GH, Fedson SE, Sayer G, Coplan MJ, et al. Elevated angiopoietin-2 level in patients with continuousflow left ventricular assist devices leads to altered angiogenesis and is associated with higher nonsurgical bleeding. Circulation 2016; 134: $141-152$.

31. Patel SR, Madan S, Saeed O, Algodi M, Luke A, Gibber M, et al. Association of nasal mucosal vascular alterations, gastrointestinal arteriovenous malformations, and bleeding in patients with continuous-flow left ventricular assist devices. JACC Heart Fail 2016; 4: 962-970.

32. Kim G, Sayer G, Ransom J, Keebler M, Katz J, Kilic A et al. Increased Bleeding risk in LVAD patients with elevated angiopoietin-2 and TNF-alpha: Analysis of the PREVENT multicenter study. J Heart Lung Transplant 2018; 37: S71.

33. Feldman D, Pamboukian SV, Teuteberg JJ, Birks E, Lietz K, Moore SA, et al. The 2013 International Society for Heart and Lung Transplantation Guidelines for mechanical circulatory support: Executive summary. J Heart Lung Transplant 2013; 32: $157-187$.

34. Marsano J, Desai J, Chang S, Chau M, Pochapin M, Gurvits GE. Characteristics of gastrointestinal bleeding after placement of continuous-flow left ventricular assist device: A case series. Dig Dis Sci 2015; 60: 1859-1867.

35. Eckman PM, John R. Bleeding and thrombosis in patients with continuous-flow ventricular assist devices. Circulation 2012; 125: 3038-3047.

36. Letzen BS, Matouk CC, Bonde P. Particle embolization for the treatment of life-threatening epistaxis in a left ventricular assist device patient. ASAIO J 2015; 61: 102-103.

37. Ono M, Sawa Y, Nakatani T, Tominaga R, Matsui Y, Yamazaki $\mathrm{K}$, et al. Japanese multicenter outcomes with the HeartMate II left ventricular assist device in patients with small body surface area. Circ J 2016; 80: 1931 - 1936.

38. Uriel N, Colombo PC, Cleveland JC, Long JW, Salerno C, Goldstein DJ, et al. Hemocompatibility-related outcomes in the MOMENTUM 3 trial at 6 months: A randomized controlled study of a fully magnetically levitated pump in advanced heart failure. Circulation 2017; 135: 2003-2012.

39. Zayat R, Khattab MA, Grottke O, Honickel M, Goetzenich A, Moza A, et al. Survival of HeartMate II patients despite cessation of anticoagulation: Outcomes and hemostatic analysis. Circ J 2018; 82: 1309-1318.

40. Szilagyi A, Ghali MP. Pharmacological therapy of vascular malformations of the gastrointestinal tract. Can $J$ Gastroenterol 2006; 20: $171-178$.

41. Loyaga-Rendon RY, Hashim T, Tallaj JA, Acharya D, Holman W, Kirklin J, et al. Octreotide in the management of recurrent gastrointestinal bleed in patients supported by continuous flow left ventricular assist devices. ASAIO J 2015; 61: 107-109.

42. Malhotra R, Shah KB, Chawla R, Pedram S, Smallfield MC, Priday AG, et al. Tolerability and biological effects of long-acting octreotide in patients with continuous flow left ventricular assist devices. ASAIO J 2017; 63: 367-370.

43. Rennyson SL, Shah KB, Tang DG, Kasirajan V, Pedram S, Cahoon W, et al. Octreotide for left ventricular assist devicerelated gastrointestinal hemorrhage: Can we stop the bleeding? ASAIO J 2013; 59: 450-451

44. Shah KB, Gunda S, Emani S, Kanwar MK, Uriel N, Colombo $\mathrm{PC}$, et al. Multicenter evaluation of octreotide as secondary prophylaxis in patients with left ventricular assist devices and gastrointestinal bleeding. Circ Heart Fail 2017; 10: e004500.

45. Ge ZZ, Chen HM, Gao YJ, Liu WZ, Xu CH, Tan HH, et al. Efficacy of thalidomide for refractory gastrointestinal bleeding from vascular malformation. Gastroenterology 2011; 141: 16291637.e1-e4.

46. Seng BJJ, Teo LLY, Chan LL, Sim DKL, Kerk KL, Soon JL, et al. Novel use of low-dose thalidomide in refractory gastrointestinal bleeding in left ventricular assist device patients. Int $J$ Artif Organs 2017; 40: 636-640.

47. Draper K, Kale P, Martin B, Cordero K, Ha R, Banerjee D. Thalidomide for treatment of gastrointestinal angiodysplasia in patients with left ventricular assist devices: Case series and treatment protocol. J Heart Lung Transplant 2015; 34: 132-134.

48. Schettle SD, Pruthi RK, Pereira NL. Continuous-flow left ventricular assist devices and gastrointestinal bleeding: Potential role of danazol. J Heart Lung Transplant 2014; 33: 549-550.

49. Netuka I, Ivak P, Tucanova Z, Gregor S, Szarszoi O, Sood P, et al. Evaluation of low-intensity anti-coagulation with a fully magnetically levitated centrifugal-flow circulatory pump: The MAGENTUM 1 study. J Heart Lung Transplant 2018; 37: $579-586$.

50. Miceli A, Glauber M. The use of new anticoagulant drugs in ventricular assist devices: Another brick in the wall? $J$ Thorac Cardiovasc Surg 2016; 151: e83-e84.

51. Meyns B, Rega F, Ector J, Droogne W, Vanhaecke J, Van Hemelrijck J, et al. Partial left ventricular support implanted through minimal access surgery as a bridge to cardiac transplant. J Thorac Cardiovasc Surg 2009; 137: 243-245.

52. Uriel N, Sayer G, Addetia K, Fedson S, Kim GH, Rodgers D, et al. Hemodynamic ramp tests in patients with left ventricular assist devices. JACC Heart Fail 2016; 4: 208-217.

53. Imamura T, Raikhelkar J, Sarswat N, Kalantari S, Murks C, Rodgers D, et al. Optimal hemodynamics during LVAD support are associated with reduced hemocompatibility-related adverse events. J Heart Lung Transplant 2018; 37: 44.

54. Sparrow CT, Nassif ME, Raymer DS, Novak E, LaRue SJ, Schilling JD. Pre-operative right ventricular dysfunction is associated with gastrointestinal bleeding in patients supported with continuous-flow left ventricular assist devices. JACC Heart Fail 2015; 3: 956-964.

55. Jabbar HR, Abbas A, Ahmed M, Klodell CT Jr, Chang M, Dai $\mathrm{Y}$, et al. The incidence, predictors and outcomes of gastrointestinal bleeding in patients with left ventricular assist device (LVAD). Dig Dis Sci 2015; 60: 3697-3706.

56. Effects of enalapril on mortality in severe congestive heart failure: Results of the Cooperative North Scandinavian Enalapril Survival Study (CONSENSUS). N Engl J Med 1987; 316: 14291435.

57. Packer M, Fowler MB, Roecker EB, Coats AJ, Katus HA, Krum H, et al. Effect of carvedilol on the morbidity of patients with severe chronic heart failure: Results of the carvedilol prospective randomized cumulative survival (COPERNICUS) study. Circulation 2002; 106: 2194-2199.

58. Mehta P, Imamura T, Belkin M, Rodgers D, Sarswat N, Kim G, et al. Neurohormonal blockade reduces adverse events during LVAD support. J Heart Lung Transplant 2018; 37: 180-181. 
59. Wang W, Zhu J, Lyu F, Panigrahy D, Ferrara KW, Hammock $\mathrm{B}$, et al. Omega-3 polyunsaturated fatty acids-derived lipid metabolites on angiogenesis, inflammation and cancer. Prostaglandins Other Lipid Mediat 2014; 113-115: 13-20.

60. Kirklin JK, Pagani FD, Kormos RL, Stevenson LW, Blume ED, Myers SL, et al. Eighth annual INTERMACS report: Special focus on framing the impact of adverse events. J Heart Lung Transplant 2017; 36: 1080-1086.
61. Zhang G, Kodani S, Hammock BD. Stabilized epoxygenated fatty acids regulate inflammation, pain, angiogenesis and cancer. Prog Lipid Res 2014; 53: 108-123.

62. Yoshioka D, Toda K, Ono M, Nakatani T, Shiose A, Matsui Y, et al. Clinical results, adverse events, and change in end-organ function in elderly patients with HeartMateII left ventricular assist device: Japanese multicenter study. Circ J 2018; 82: 409418. 